\title{
Italian weather scientists and sports scientists - is there a link?
}

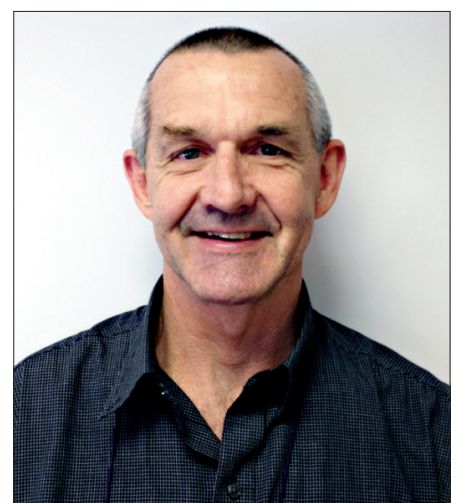

A few weeks ago an Italian court convicted seven weather scientists for manslaughter. ${ }^{1}$ Their crime? They failed to adequately warn residents before a tremor struck central Italy in 2009. More than 300 people were killed as a result of the quake. The scientists were sentenced to 6 years' imprisonment for giving 'inexact, incomplete and contradictory information' about whether small tremors felt in the weeks and months before the earthquake constituted grounds for a more serious warning about an impending earthquake. Although the scientists claimed that the science of tremors was not sufficiently reliable to predict earthquakes, the judge did not share this view.

This got me thinking about the disciplines of sports medicine, physical activity, health and sporting performance, and I wondered if there would ever be a case when practitioners in these disciplines were held accountable for any event that they failed to predict accurately. My personal interest lies in chronic fatigue, specifically being able to anticipate or predict the onset of chronic fatigue before the symptoms become serious, affecting health and performance. I have sometimes described my role akin to that of a weather forecaster who gathers information about prevailing conditions and then makes a decision about what is going to happen in the future. Does that put me in the same category as these Italian scientists if I get it wrong? This is a relatively innocuous example; lives are unlikely to be lost if the prediction is incorrect. However, there are many far more serious examples that may have life-threatening consequences for an athlete. For example, it is well known that repetitive head injuries have longterm consequences that manifest years after the athlete stops playing sport. How soon will it be before an athlete who has experienced repetitive head injuries as a result of playing sport forms a strong case, and charges those administrators or service providers to whom he had given his trust during the competitive years? What about an athlete who has developed arthritis in a joint as a result of an injury during a competition and then rehabilitated with an accelerated programme so that he/she could get back into competition? With our current information, does the athlete not have a case against the practitioners involved in the rehabilitation?

The scenarios extend beyond high-level sport. What about the general practitioner's diabetic patient who lodges a complaint that the GP did not give adequate advice about the importance of nutrition and regular physical activity in managing the condition? The list goes on and on. Some other examples are considered and unpacked in the paper 'Lifetime injury prevention: The sport profile model', which is published in this edition. ${ }^{2}$ This article was published in the British Journal of Sports Medicine (BJSM) and rated as an editor's choice paper. BJSM have given us permission to re-publish editor's choice papers in the South African Journal of Sports Medicine.

The paper shows that participating in sporting activities carries a risk of injury ranging from trivial to large. Some of these risks are known and quantifiable at the onset, others are not. As more information about physical activity and health becomes available, so the responsibility of the practitioners who are administering and prescribing the treatments increases. Part of this responsibility is to communicate the risk of injury to the patient or athlete. The participant needs to be sensitised to all these risks so that an informed decision can be made about whether participation in the sport is justified.

We are going through a phase of seeing harsh measures being taken against athletes who have been caught doping, including forcing the athlete to return the prize money won while they were using drugs to enhance performance. With the high-profile case of Lance Armstrong, a precedent has been set. The bar has been raised for achieving fairness in sport and it is likely to become the norm. The same argument can be made for service providers who are tasked with looking after the well-being and health of athletes. The bar has also been raised for them. How soon will a service provider be asked to return money for below-par services rendered to an athlete, or for services that did not consider or take advantage of the most current information?

Unfortunately all these points suggest that we are likely to see an increasing number of litigation cases seeking compensation for longterm health problems arising from sports injuries. Let's just hope that the legal authorities do not take such a drastic stance as the Italian authorities took against the weather scientists.

\section{Mike Lambert \\ Editor-in-Chief}

1. Camilli A. 7 Jailed for failing to predict quake. http://wwwiol.co.za/news/world/7jailed-for-failing-to-predict-quake-1.1408815\#.UJ1ctqXz7S- (accessed 23 October 2012). 2. Webborn N. Lifetime injury prevention: The sport profile model. Br J Sports Med 2012;46(3):193-197. [http://dx.doi.org/10.1136/bjsports-2011-090417]

S Afr J SM 2012;24(4):106. DOI:10.7196/SAJSM.363 